Gero Gerber

\title{
ALARM SYSTEMS IN BUILDINGS - INVESTIGATION OF EFFECTIVENESS DEPENDING ON BUILDING TVPE AND USER PROFILE
}

Alarm systems are used to warn passengers and employees in railway stations, airports, logistics facilities and administrative buildings of hazards; in this way, they are instructed to rescue themselves. A large online survey conducted in Germany in 2018 has shown that often sounding the alarm does not have the desired effect. The research presented in this article investigates dependence of an alarm effectiveness on type of building, user profile and type of the alarm system.

In this paper, general and building-specific measures, using which the effective sounding of the alarm and optimal behaviour of the building users in the case of danger can be achieved, are presented.

Keywords: hazard warning, alarm systems, effectiveness, building type, user profile

\section{Introduction}

Goods and passengers are mainly transported by road, rail, waterway or air. Nevertheless, the majority of transport workers do not work in vehicles, but in buildings. These include:

- railway stations,

- airports

- logistics halls,

- administration buildings.

All the aforementioned types of buildings are special buildings. Compared to normal residential buildings, various factors can lead to an increased risk of danger for these types.

In the case of danger, all the affected persons must quickly and effectively be informed about the dangerous situation to give them the opportunity to bring themselves to safety. In large and complex buildings, rapid information transmission only works with the help of alarm systems. The experience reports of numerous experts have shown that in many cases, even well-functioning systems do not lead to the intended reaction.

Example: In 2015, a medium-sized regional railway station in southern Germany was renovated. Acoustic signalling devices were installed throughout the entire building to provide an alarm in the event of a fire. The functional test of the alarm was performed without prior notice during a normal station operation. The warning signals sounded throughout the entire building. But how did people react? Neither the passengers nor the employees left the station building. Nobody took the alarm signal seriously, and nobody reacted as intended.
Such and similar experiences led us to the idea of scientifically investigating the effectiveness of alarm systems depending on the building type, user profile and type of the alarm system. The technical literature presents studies on the effect and design of danger signals. The books titled 'Human factors in alarm design' [1] and 'Design of danger signals' [2] contain a well-structured summary of the research results. Influence of the acoustic parameters of signals on the reaction time was investigated in a British Standard study [3].

The investigation of the effectiveness of entire alarm systems broke new ground.

\section{Tasks of alarm systems}

The actions required in a hazardous situation depend on the nature of the hazard (Figure 1). In the event of a fire or bomb alarm, all people should leave the building as quickly as possible. If the danger is outside (e.g. chemical alarm or storm), people must remain inside the building. In an amok situation, all endangered people must seek shelter in the building and barricade themselves in

The aim of a technical alarm is always to save time and enable self-rescue [4, p. 245-247].

\section{Possibilities of sounding the alarm}

In small- and medium-sized buildings, it is usually sufficient for people to alert each other of a danger. This can be done at random or according to organisational specifications (e.g. with alarm chains or evacuation

Gero Gerber

Hohenfelden, Germany

E-mail of corresponding author: Gero.Gerber@factum-gmbh.com 


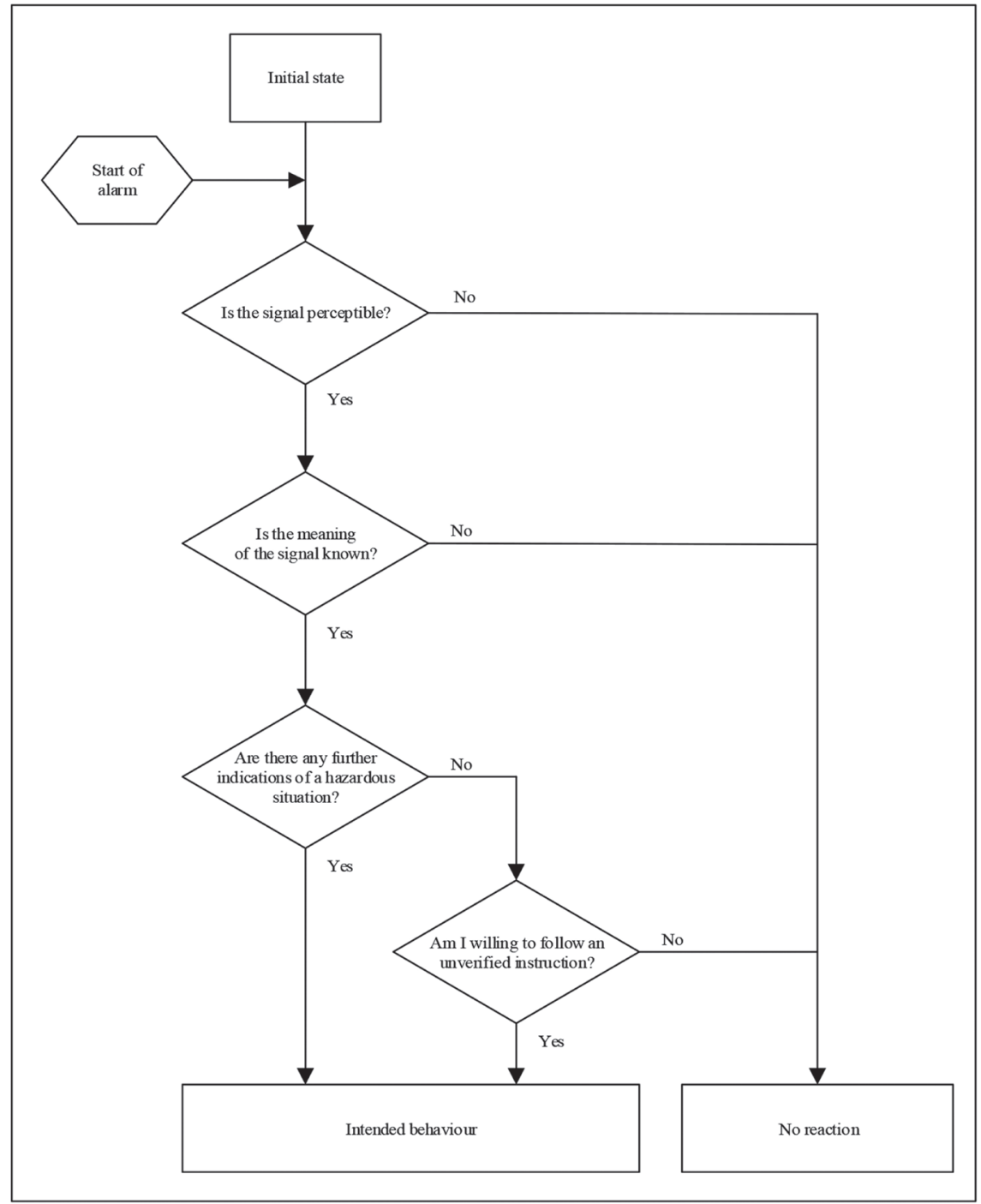

Figure 3 Decision making

assistants). A personal alarm will take too long if the buildings become larger. Technical aids, such as fire bells, sirens or megaphones, must be used. The range of simple alarm devices for extensive and complex buildings is too short. Alarm systems must be installed to quickly reach all the endangered persons. Those systems must consist of one or more triggering devices, a control centre with a power supply and the alarm devices (Figure 2). Often, the voice alarm systems are preferred in buildings without a fixed user group. The book titled 'Speech Alarm Systems and Electroacoustic Emergency Warning Systems' contains detailed basic information and notes on planning [5].

In practice, the following plant types are particularly used:

- $\quad$ systems with acoustic and/or optical signalling devices,

- voice alarm systems,

- $\quad$ systems for the silent alarming the personnel.

Table 2 shows the typical areas of application. Fields with "X" show typical applications. An "(X)" means that the solution is rarely used.

\section{Normative requirements}

Standards of the EN54 series "Fire alarm systems" contain the technical requirements for the components of the fire alarm and voice alarm systems. EN 54 Part 32 contains specifications for the internal alarm of fire alarm systems. EN54 Part 16 specifies the requirements for voice alarm control panels [6]. Requirements for planning, installation and operation of the systems are defined in national standards. In Germany, DIN 14675 "Fire alarm systems - Construction and operation" [7] and DIN VDE 0833-4 "Hazard alarm systems - Specifications for voice alarm systems" are the standards [8]. In the US, alarm systems are built according to the guideline, NFPA72. Chapter 18 of the NFPA is about notification appliances [9, p. 109-115].

The standards described give recommendations for alarm sound levels and speech intelligibility. None of the above standards contains criteria for assessing the effectiveness of the alarm systems. 


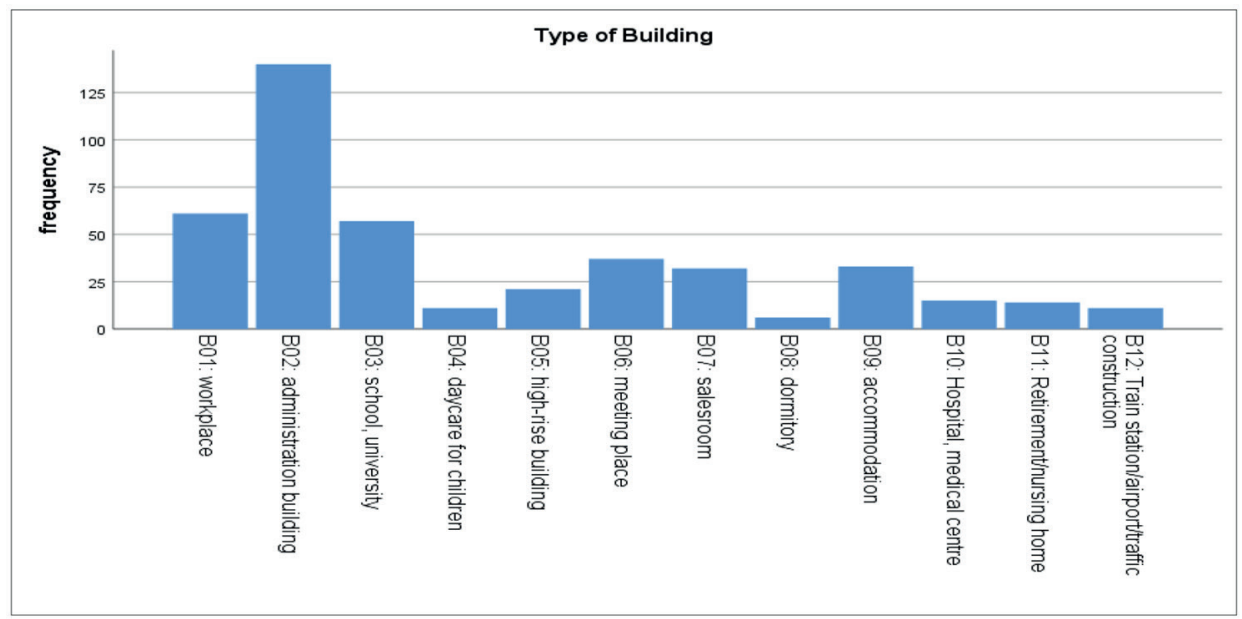

Figure 4 Frequencies of the building types in the case reports

\section{Human behaviour in hazardous situations}

Human behaviour patterns in a danger situation are ancient and essential for survival. An individual recognises a threat and has to decide what to do in a very short time. The two main options are flight or fight. In social communities of humans, but also of animals, it has proven successful to warn the other individuals of the group, as well. The warning can be an invitation to flight or a call for support in the fight.

The term "alarm" has many meanings in psychology, technology and colloquial language. Psychologist Dr Neville Stanton writes about this in the introductory article of his anthology "Human Factors in ALARM DESIGN": A frequently given definition of an alarm is "a significant attractor of attention"! [1, p. 2].

The first prerequisites for a correct reaction is the perception of the alarm signals. Further preconditions are:

- $\quad$ knowledge of the meaning of the danger signal,

- willingness to act.

Figure 3 shows possible ways of decision-making.

\section{Expectations regarding the effectiveness of alarm systems}

Effectiveness of a measure describes the ratio of the real result to the desired goal and can take values between 0 and 1 or $0 \%$ and $100 \%$.

Effectiveness $=\frac{\text { result }}{\text { goal }}$.

The present paper focuses on effectiveness of the alarm systems. The highest effectiveness is achieved when all the alarmed persons behave as intended. If no one reacts, the effectiveness is zero. Effectiveness of an alarm system can be described with the following formula:

Effectiveness $=\frac{\text { Number of persons behaving as intended }}{\text { Number of persons to be alarmed }}$.
However, two questions should be answered: What are expectations regarding the effectiveness of an alarm system? How can this alarm system be evaluated? These questions are answered by conducting interviews with 12 experts in this field, including professors at universities, fire protection planners, senior fire brigade employees and test experts for safety systems.

The experts agreed that alarm systems must be planned and built in such a way that, normally, every person present can receive the alarm signal. According to most experts, exceptions are permitted if people with headphones and loud music or by taking alcohol, drugs or sleeping pills are able to disconnect themselves from their environment. For people with hearing impairments and those who wear hearing protection at work, the alarm must be ensured by means of organisation or other aids.

The experts also agreed that the objective is for all the alarmed persons to react as intended, even if this is not always possible in practice. Certain groups of people may not be able to react as intended. These include

- small children,

- mentally ill people,

- persons with physical disabilities.

The required effectiveness of an alarm in a building depends on how many people who do not respond as intended can be rescued in an acceptable time by the emergency services.

Example: If up to 50 people can be rescued by the fire brigade in an acceptable time in the event of a fire in a cinema with 1000 people, the effectiveness of the alarm must be $95 \%$.

It is not advisable to specify a fixed set point of effectiveness for all the building types. Even for a concrete building it is difficult to fix a certain number in the planning phase. Nevertheless, a great agreement among the respondents was that in order to achieve the protection goal, the effectiveness achieved must be $90 \%$ or higher, in most cases.

When evaluating the case reports from the survey, all examples with an effectiveness of $<90 \%$ were rated as insufficient. 


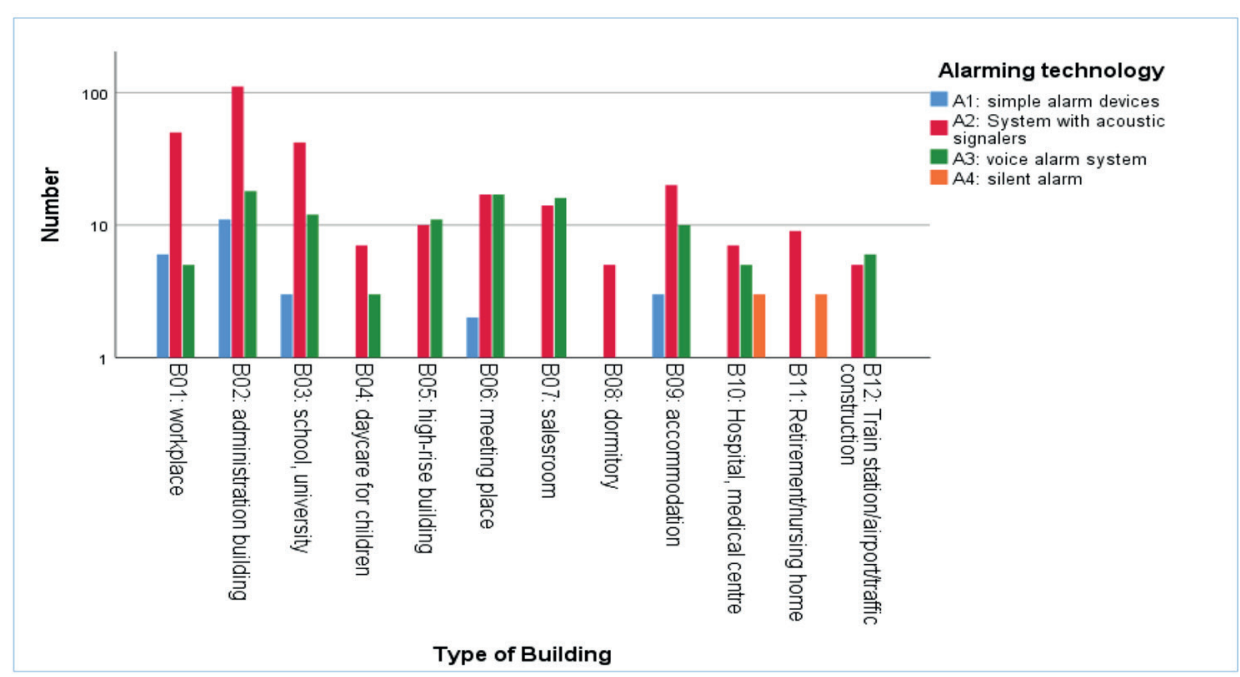

Figure 5 Distribution of alarm systems in buildings

\section{Investigation of effectiveness}

The central part of this research work was the collection and evaluation of the case reports of real alarms in buildings. The data were collected in a Germany-wide online survey between 30.11.2017 and 25.01.2019. The participants were all the people with professional experience in fire protection or security technology. Of the 609 data records, 438 fulfilled all the formal requirements to be included in the survey. Case reports from the second hand or with incomplete information were not used. Only $16.5 \%$ of the case reports were related to an announced practice alarm, indicating that in $83.5 \%$ of the cases, the alarm came as a surprise to those affected. The persons behaved as in a real danger case.

Figure 4 shows distribution of the building types within the case reports. A total of 11 case reports represent railway stations, airports and traffic structures. The category 'workplaces' contains at least 11 case reports from freight forwarding and logistics halls. The proportion of transport companies cannot be exactly determined in the case of administrative buildings. However, the specific user sector is likely to have only a minor influence on the behaviour of users in the event of an alarm; hence, the results of the study can also be applied to administrative buildings in the transport sector.

The survey results showed in what frequency the types of alarm systems are used in different building types (Figure 5).

The second step was to analyse how the effectiveness of an alarm system depends on the building type, user profile and type of alarm system.

Examination of the three factors with the Pearson Chi-square test showed no significant correlation within the three factors. All the three factors had to be individually examined.
The user profile and the building type have a significant influence on effectiveness of the alarm. The type of alarm system has only a minor influence.

Overall, the average effectiveness of the alarm systems is below $90 \%$ for all the user profiles and in all the building types, with the exception of day care centres for children and is therefore inadequate. Buildings with a fixed circle of users (e.g. logistics halls and administration buildings) performed significantly better at around $80 \%$ than buildings with many non-local users (e.g. airports and railway stations), which reached around 40\%. (Figures 6 and 7).

The user profile and building type are closely related. Nevertheless, the statistical investigation has shown that they are independent variables. The error bar displayed in the columns shows that $95 \%$ of all the results are within this range.

Interestingly, there were case reports for each type of building and user profile in which the alarm worked very well. This indicates that there are other important influencing factors in addition to the factors investigated. In order to narrow these down, the expert interviews and the comments of the survey were examined qualitatively.

Both the experts interviewed and the survey participants cited organisational deficits as the main reason for the insufficient effectiveness.

In cooperation with the Chair of Psychology at the University of Erfurt, the psychological aspects of alerting were investigated and the following findings were obtained:

- Previous experiences with alarm situations showed no significant influence on the behaviour in the case of a fire alarm.

- Occurrence of frequent alarms without any real danger results in unserious responses to danger signals $[10$, p. 33-35].

- By changing the acoustic properties of the alarm signal, only slight improvements in reaction time are possible [11, p. 20-23]. 


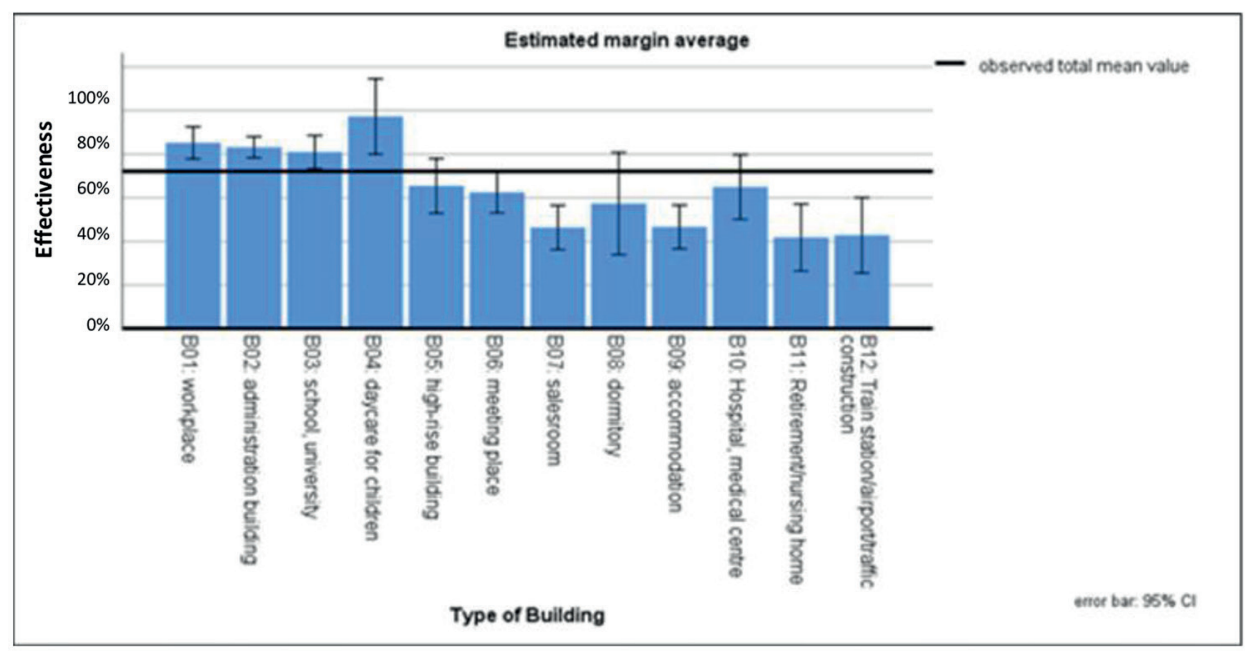

Figure 6 Effectiveness of alarm systems for various building types

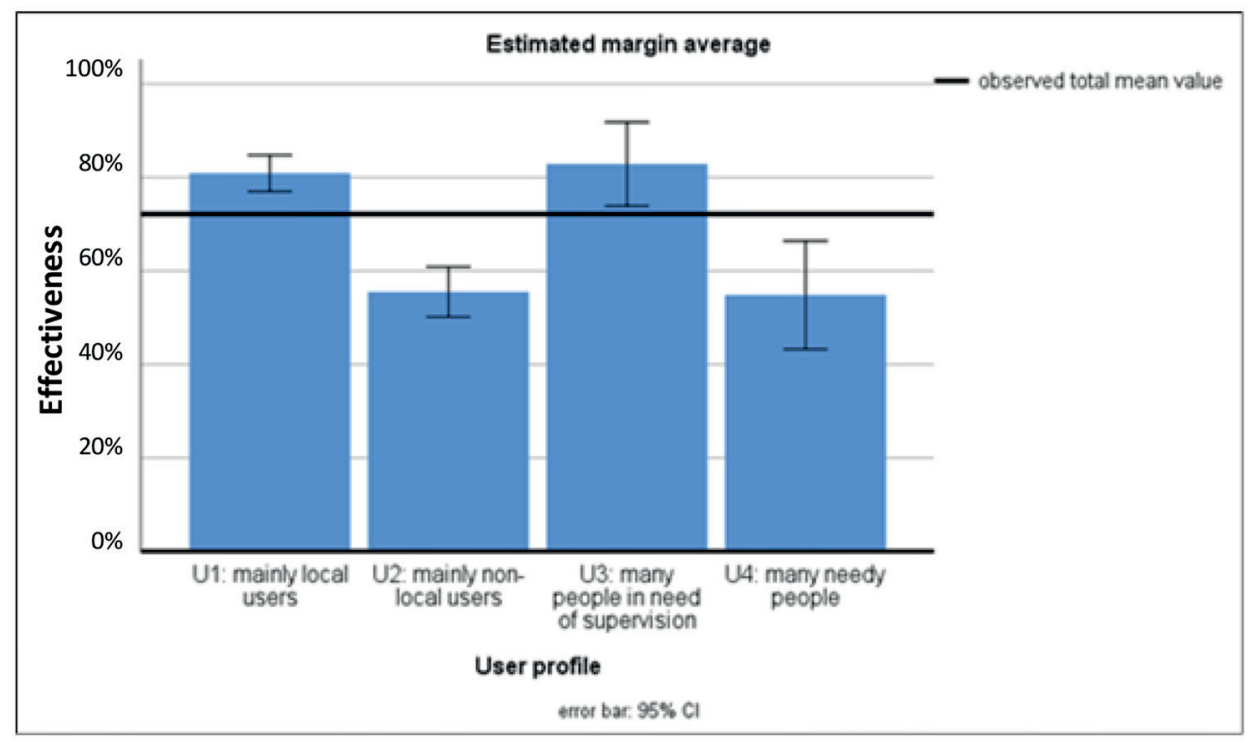

Figure 7 Effectiveness of alarm systems for various user profiles

\section{Ways to improve effectiveness of the alarm systems}

The following recommendations for planning and operation of the alarm systems are given based on the expert interviews, hints of the survey participants and own experiences.

\subsection{General measures for all building types}

In the event of a danger, an alarm system can only be highly effective by a coordinated interaction of technical and organisational measures. The most important technical tasks include the following:

- $\quad$ ensuring signal perceptibility in the entire alarm area (volume, speech intelligibility and visibility),

- use of suitable signals (known tone sequences, multilingual text announcements and comprehensible visual displays),
- $\quad$ high plant availability and replacement measures in the event of malfunctions.

The most important organisational measures include the following:

- regular training and instruction of all the permanent users of the building,

- regular exercises under realistic conditions (unannounced test alarms),

- consistent evaluation of exercises (commendation, criticism and deficit identification and elimination).

\subsection{Administrative buildings}

Administrative buildings do not pose a major fire protection challenge in many cases. The probability of a hazardous situation is low. Everyone is awake, mobile and able to quickly react when needed; therefore, no fire alarm or alarm systems are installed in many small- and mediumsized administrative buildings. Accordingly, investigation of 
the alarm systems' effectiveness is primarily related to large and complex administrative buildings.

Use of the alarm systems with simple acoustic and, if necessary, optical signalling devices is sufficient in most cases. Once the perceptibility of the signal has been ensured at all the workplaces, break rooms and sanitary rooms, only the organisational measures need to take effect. Unfortunately, the willingness to react to an alarm signal is not particularly pronounced among office employees. Hence, regular instruction and exercises, which are also evaluated, are particularly important.

\subsection{Workplaces}

Workplaces always have a fixed circle of users. The above-described measures are applicable. Cargo ports and logistic halls often have other acoustic signals in addition to the alarm signal. The following technical measures can be used to achieve an effective alarm system in the event of a danger:

- use of additional optical alarm devices (flashlights or large-surface illuminated displays),

- plant shutdown,

- use of displays on the control station of the plant technology,

- cyclic switching of room lighting,

- use of pager or portable phones with a vibration alarm,

- equipping of evacuation assistants with inscribed warning vests and whistles,

- $\quad$ additional use of powerful motor sirens.

\subsection{Railway stations and airports}

The problem in railway stations and airports is that a very small group of permanent employees is confronted with a large group of people unfamiliar with the place. The success of the alarm depends to a large extent on the correct behaviour of this small group. Regularly instruction and training this group are the basic prerequisites for achieving the protection goals. Recommendations for special building types are given below.

Large traffic structures, such as railway stations and airports, are designed for the simultaneous and short-term presence of many people who are unfamiliar with the place and are mostly in motion. Many foreign travellers can stay in large cities and transport hubs.

Alerting travellers is a special challenge. Passengers who hear a hazard warning, but do not recognise a hazard would much rather proceed in their aircraft or train than follow a presumably unfounded instruction.

Experience has shown that simple acoustic signalling devices are ineffective in such facilities. They garner attention briefly; then, they are ignored. After a few minutes, they are perceived as annoying. Even a high-quality voice alarm system does not guarantee effective alerting if not accompanied with organisational measures.

The following recommendations could be extracted from the experiences of the survey participants and the interviewed experts:

- If possible, the first step should only be to alarm the staff (e.g. via coded announcements).

- If a hazard condition is verified, a personal situationrelated announcement should be made by the person responsible for safety.

- An automatic hazard announcement should be made if the pre-alarm has not been acknowledged within a predefined time.

- Evacuation helpers, who are recognisable as authority figures, should call on travellers, employees and shop assistants to go to safety. This task can be performed by uniformed railway officials, police officers, security personnel or employees with marked warning vests.

\section{Summary}

Alarm systems are designed to quickly inform people in large buildings about a hazardous situation and induce them to take a certain action. In practice, this goal is not achieved in many cases. The situation is particularly critical in buildings without the fixed user groups, such as railway stations and airports.

Building- and user-specific organisational measures are required in addition to suitable alarm systems to achieve the desired protection goal. The decisive factors herein are regular and practical exercises, their professional evaluation and elimination of identified deficits.

\section{Acknowledgement}

The research was supervised by Prof. Dr Ales Dudacek from the Technical University of Ostrava. Prof. Dr Jorg Reintsema from Cologne University of Applied Sciences was recruited as the second supervisor. Professor Dr Tilmann Betsch of the University of Erfurt took over the consultation to the psychological aspects. I would like to thank all professors, the interview partners and the participants of the survey for their support.

\section{References}

[1] STANTON, N. A human factors approach. In: Human factors in alarm design. STANTON, N. (ed.). London, Washington, D.C: Taylor \& Francis, 1994, p. 1-14. 
[2] MALTER, B., GUSKI, R. Gestaltung von Gefahrensignalen / Design of hazard signals(in German). Bremerhaven: Wirtschaftsverl. NW, 2001. Schriftenreihe der Bundesanstalt fur Arbeitsschutz und Arbeitsmedizin Fb/ Series of publications from the Federal Institute for Occupational Safety and Health. ISBN 935-3-89701-780-6.

[3] BSI. DD 240, 1997, Fire Safety Engineering in Buildings.

[4] GERBER, G. Brandmeldeanlagen. Planen, Errichten, Betreiben / Fire alarm systems. Planning, building, operating (in German). 5. ed. Heidelberg: Huthig, 2018. ISBN 978-3-8101-0464-9.

[5] SIMON, A. Sprach alarm anlagen und elektroakustische Notfallwarnsysteme. Neuausgabe des beliebten Fachbuchs "Fachkraft fur Sprach alarm anlagennach DIN 14675" / Voice alarm systems and electro-acoustic emergency warning systems. New edition of the popular specialist book "Specialist for voice alarm systems according to DIN 14675" (in German). Heidelberg: Huthig, 2018. ISBN 978-3-8101-0454-0.

[6] DIN Deutsches Institut fur Normung. EN54-16, DIN EN 54-16:2008-06, Brandmeldeanlagen_- Teil_16: Sprachalarmzentralen; Deutsche Fassung EN_54-16:2008 / German institute for standardization. EN54-16, DIN EN 54-16: 2008-06, fire alarm systems_- part_16: voice alarm centers; German version EN_54-16:2008 (in German). Berlin: Beuth Verlag GmbH.

[7] DIN DeutschesInstitut fur Normung. 14675-1, Brandmeldeanlagen / German institute for standardization. 14675-1, fire alarm systems (in German). Berlin: Beuth Verlag GmbH.

[8] DKE. 0833-4, Gefahren meldeanlagen fur Brand, Einbruch und Uberfall / Alarm systems for fire, burglary and robbery (in German). Berlin: VDE-Verlag.

[9] NFPA 72 National fire alarm and signaling code handbook. 8 ed. Quincy, MA: National Fire Protection Association, 2015. ISBN 978-145591201-8.

[10] HEHN, K. Decision making during fire alarms. The role of experience and perceived risk. Bachelor thesis. Erfurt, 2019.

[11] DIECKMANN, T. J. Das Spiel mitdem Feuer. Wie Alarmsignale die menschliche Reaktionsbereitschaft und die wahrgenommene Dringlichkeit beeinflussen / Playing with fire. How alarm signals affect human responsiveness and perceived urgency (in German). Bachelor thesis. Erfurt, 2019. 